\title{
Plaka Tip Isı Değiştiricide Grafit/Saf Su Nanoakışkan Kullanımının Isıl Performansa Etkisi
}

\author{
Muhammet Kahveci ${ }^{1}$, Tarkan Koca ${ }^{2 *}$ \\ ${ }^{1}$ Inonu University, Faculty of Engineering, Departmant of Mechanical, Malatya, Turkey, (ORCID: 0000-0003-3991-0960), m kayfeci1984@hotmail.com \\ ${ }^{2 *}$ Inonu University, Faculty of Engineering, Departmant of Mechanical, Malatya, Turkey, (ORCID: 0000-0002-6881-4153), tarkan.koca@inonu.edu.tr
}

(Illk Geliş Tarihi 22 Nisan 2021 ve Kabul Tarihi 27 Haziran 2021)

(DOI: $10.31590 /$ ejosat.925777)

ATIF/REFERENCE: Kahveci, M., Koca, T. (2021). Plaka Tip Isı Değiştiricide Grafit/Saf Su Nanoakışkan Kullanımının Isıl Performansa Etkisi. Avrupa Bilim ve Teknoloji Dergisi, (25), 400-405.

\section{Öz}

Isı transferini artırmak ve basınç düşüş değerini en aza indirmek, 1sı değiştirgeçlerinin ısıl performansını iyileştirmek açısından önemli olup üzerinde çok sayıda çalışma yapılan bir konudur. Isı transfer oranını artırmak için, üstün termofiziksel özellikli nanoakışkanlar 1Sı değiştiricilerinde kullanılmaktadırlar. Bu çalışmada birleşik sıcak su hazırlama sisteminde bulunan plakalı 1sı değiştiricisinde grafitsu nanoakışkanı kullanımının ısı transferine, etkinlik katsayısına ve iyileştirme oranına etkisi deneysel olarak incelenmiştir. Çalışmada soğuk su debileri 4, 5, 6,7 1/dk, sıcak akışkan giriş sıcaklıkları ise $40,45,50,55,60^{\circ} \mathrm{C}$ olarak alınmıştır. Elde edilen sonuçlara göre hacimce $\% 0.25$ nanoakışkan oranında en yüksek iyileştirme oranı 4 l/dk debi değerinde $\% 9,42$ olarak elde edilirken, debi arttıkça 1sı transferinin arttığı ve iyileşme oranının düştügü belirlenmiştir.

\section{The Effect of Graphite/Pure Water Nanofluid Usage on Thermal Performance in Plate Type Heat Exchanger}

\begin{abstract}
Increasing the heat transfer and minimizing the pressure drop value is important in terms of development the thermal performance of heat exchangers, and it is a subject that a large number of studies conducted. To increase the heat transfer rate increase the heat transfer rate, nanofluids with superior thermophysical properties are used in heat exchangers. In this study, the effect of graphite-water nanofluid use on heat transfer, efficiency coefficient and improvement rate in the plate heat exchanger in the combined hot water preparation system was investigated experimentally. In the study, cold water flows were taken as 4, 5, 6, 7 1/min and hot fluid inlet temperatures as $40,45,50,55,60^{\circ} \mathrm{C}$. According to the results, while the highest improvement rate was achieved at a rate of $0.25 \%$ nanofluid by volume, $9,42 \%$ at a volumetric flow rate of $41 / \mathrm{min}$, it was determined that the heat transfer increased and the recovery rate decreased as the flow rate increased.
\end{abstract}

Keywords: Nanofluid, Plate heat exchanger, Graphite, Pure water, Effectiveness 


\section{Giriş}

Gelişen teknoloji ile birlikte endüstriyel alanda kullanılan makinalarda büyük değişimler olmuştur. Kullanılan ekipmanların 1sitma, soğutma talepleri bir taraftan artarken diğer taraftan da boyutlarının minyatürleşmesi istenmektedir. $\mathrm{Bu}$ nedenle endüstriyel makinalarda ısıl verimi arttırmak için çalışmalar yapmak kaçınılmaz hale gelmiştir. Malzeme biliminin gelişmesiyle birlikte nano büyüklükte partiküller üretilebilir hale gelmiştir. Nano boyuttaki malzemeler daha dayanıklı, daha hafif ve daha iyi ısı ve elektrik iletme özelliklerine sahiptirler. Bütün bu özelliklerinden dolayı nano partiküller baz akışkana ilave edilmeye başlanmış ve nanoakışkanlar üretilmiştir. Nanoakışkan; akışkan içerisine nano büyüklükteki parçacıkların süspanse edilmesi ile elde edilir. Bütün bu alanlarda kullanılan su, yağ, glikol ve etilen gibi sıvılar baz akışkan, içerisine ilave edilen nano büyüklükteki parçacıklar ise nano parçacık olarak adlandırılmaktadır. Temel akışkan olarak çoğunlukla su kullanılmasına rağmen etilen, glikol ve mineral yağ da kullanılmaktadır. Parçacık olarak ise metal ve metal oksitler kullanılmaktadır. Yaklaşık son 20 yıldır 1sı transferinin iyileştirilmesi amacıyla milimetre boyutunda parçacıklar baz akışkana eklenmektedir. Ancak bu parçacıklar kullanılan sistemde aşınmalara, basınç düşüşlerine, aşırı gürültü, titreşim ve çökelme gibi sebeplere yol açmaktadır. Buna rağmen kullanılan sistemde 1S1 transfer hızındaki artış bu olumsuzlukların göz ardı edilmesine neden olmuştur. Akışkan içine süspanse edilen parçacık, akışkanın yüzey alanını ve 1sıl kapasitesini arttırmaktadır. Bütün bu nedenlerden dolayı günümüzde bilim insanları nanoakışkanlar üzerine yoğun bir şekilde çalışmaktadır.

Chun ve ark., (2008), çift borulu paralel akışlı bir 1S1 eşanjöründe laminar akış rejiminde 1sı eşanjör sisteminden akan alümina nano parçacık ve transformatör yağından yapılmış nano akışkanların konvektif ısı transfer katsayısını araştırmışlardır. Deneysel veriler, sıvıya nano partiküllerin eklenmesinin, sistemin laminer akıştaki ortalama 1S1 transfer katsayısını arttırdığını göstermiştir. Nano partiküllerin yüzey özellikleri, partikül yükü ve partikül şeklinin nano akışkanların 1sı transfer özelliklerini arttırmak için en önemli özellikler olduğunu belirtmişlerdir. Bhattad ve ark., (2018), 1sı transferi ve basınç düşüşü özellikleri üzerindeki etkisini araştırmak için farklı konsantrasyonlarda hibrit nanoakışkan $\left(\mathrm{Al}_{2} \mathrm{O}_{3}+\right.$ MWCNT / su) kullanarak plakalı 1sı eşanjörü üzerinde sayısal ve deneysel araştırmalar yapılmıştır. Hibrit nano akışkan kullanarak, 1sı transfer katsayısı \%39,16 artmış ve pompalama gücünde \%1,23'lük bir artış olmuştur. Bu nedenle baz akışkan yerine hibrit akışkan kullanılabileceğini değerlendirmişlerdir. Sarafraz ve Hormozi (2016), Chevron tipi bir 1S1 eşanjörü içindeki çok duvarlı karbon nanotüp nanoakışkanlara, zorlanmış konveksiyonla ısı transferini artırmak için deneysel bir çalışma yapmışlardır. Su içinde çok duvarlı karbon nanotüplerin varlığı, saf su ile karşılaştırıldığında 1 sıl iletkenlik katsayısı \%68'e artmıştır. Zamzamian ve ark., (2011), alümina-etilen glikol ve bakır oksit-etilen glikol nanoakışkanlarını, farklı konsantrasyonlarda hazırlamışlar ve nanoakışkanların 1sıl özelliklerini tespit etmek için türbülanslı akışta, $45^{\circ} \mathrm{C}, 60^{\circ} \mathrm{C}$ ve $75^{\circ} \mathrm{C}$ 'lik üç çalışma sıcaklıklarında çift borulu ve plakalı 1sı eşanjörlerinde deneyler yapmışlardır. Yapılan deneylerde en büyük ve en küçük artışlar sırasıyla \%49 ve \%3 olarak görülmüştür. Varyenli ve Sarı (2016), yaptıkları çalışmalarında saf su- MgO kullanmışlardır. Yapılan deneylerde MgO-su nanoakışkanında debi artışına bağlı olarak etkinlik katsayısı artmıştır. Huang ve ark., (2016), alümina nano partiküller ve çok duvarlı karbon nanotüpler içeren hibrit bir nanoakışkan karışımının 1sı transferi ve basınç düşüşü özelliklerini, plakalı 1S1 eşanjöründe deneysel olarak incelemişlerdir. Aynı akış hızında hibrit nanoakışkan karışımının 1S1 transfer katsayısı $\mathrm{Al}_{2} \mathrm{O}_{3}$-su nanoakışkan ve suyunkinden daha yüksek olduğu tespit edilmiştir.

Yapılan bu çalışmada saf su ve grafit-su nano akışkanı deney akışkanı olarak seçilmiştir. Nanoakışkan elde edilirken grafitin hacimsel konsantrasyonu \%0,25 olarak alınmıştır. Soğuk su debisine bağlı olarak nanoakışkanın ısı transferi, etkinlik katsayısı ve iyileşme oranı incelenmiştir. Soğuk su debileri 4, 5, 6, 7 1/dk olarak ayarlanmış olup, sıcak akışkan giriş sıcaklıkları ise 40, 45, $50,55,60^{\circ} \mathrm{C}$ olarak alınmıştır. Yapılan deneyel çalışmada değişkenler literatüre uygun olarak seçilmiştir. Çalışmada konut 1sitılmasında kullanılan birleşik sıcak su hazırlama sistemi kullanılmıştır. Isı değiştiricisi tipi plaka tip eşenjördür. Deneysel çalışmalarda plakalı 1sı değiştiricilerinde nanoakışkan kullanımının 1sı transferine etkisi değerlendirilmiş olup etkinlik katsayıları ve iyileştirme oranları hesaplanmıştır.

\section{Materyal ve Metot}

\subsection{Deneysel Sistem}

Deney seti İnönü Üniversitesi Mühendislik Fakültesi Makine Mühendisliği Isı Laboratuvarına kurulmuş ve deneyler gerçekleştirilmiştir. Yapılan çalışmada saf su içerisine hacimce $\% 0,25$ oranında grafit nano partikülü eklenerek, 1s1 transferi, etkinlik katsayısı ve iyileştirme oranı incelenmiştir. Deney setinin şematik gösterimi Şekil 1'de verilmiştir. Deney seti; 8 plakaya sahip levhalı tip ısı değiştirici, 1sıtıcı sistem, debi ölçer, sıcaklık ölçer, veri kayıt sistemi, bilgisayar ve sirkülasyon pompasından oluşmaktadır. Isıtma sistemi LPG'li tip olup farklı 1sı yüklerine ayarlanabilecek şekilde dizayn edilmiştir. Akışkan sirkülasyonunu sağlamak ve akışkanı basınçlı şekilde sistemde dolaştırmak için 3 kademeli pompa kullanılmıştır. Pompanın debisi 18 l/dk' dır. Deney setine giren akışkanın debisini ayarlayabilmek için giren soğuk akışkanın girişine 1 adet ayarlı tip vana yerleştirilmiştir. Vananın hemen çıkışında, suyun hacimsel debisini ölçebilmek için debimetre kullanılmıştır. Sisteme giren soğuk akışkanın, sistemden çıkan sıcak akışkanın, plakalı eşanjöre giren soğuk ve sıcak akışkanın sıcaklığını ölçmek için 4 adet Tekon marka K tipi termokupl kullanılmıştır. Plakalı 1Sı değiştirici içindeki akışkanı tahliye etmek ve sisteme 1,5 bar olacak şekilde nanoakışkan doldurabilmek için için U by-pass hattının her iki tarafına da vanalı tip giriş çıkış hattı koyulmuştur. Sisteme hazırlanmış olan akışkanın doldurulabilmek için basıncı elle arttırılabilen, kapasitesi 4 bar olan ve sıvı akışkan koyulabilecek hazneye sahip el pompası eklenmiştir. Sisteme nanoakışkan bu pompa vasıtasıyla doldurulmuştur. 4 adet Tekon marka termokupldan gelen bilgiler Picolog marka TC-08 modelindeki veri kayıt cihazının yardımıyla bilgisayara aktarılmıştır. 


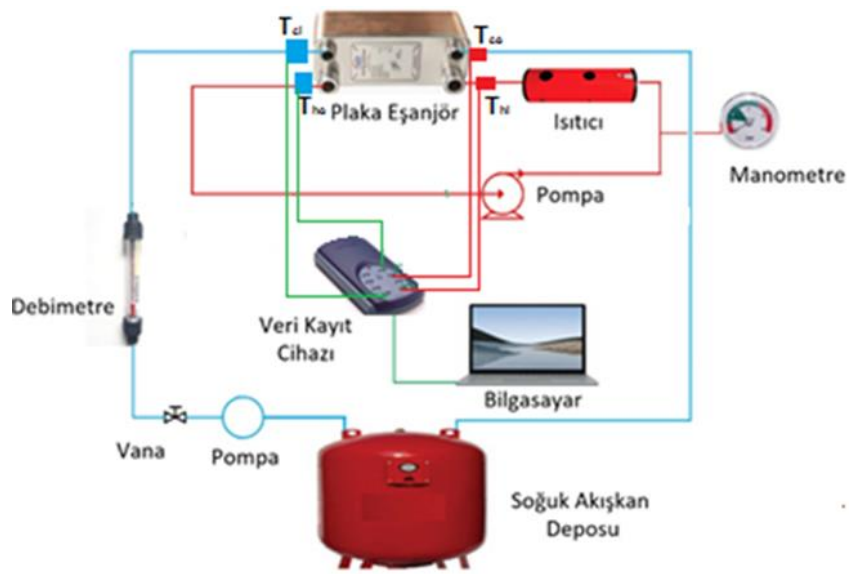

Şekil 1. Deney setinin şematik gösterimi

Deney setinin farklı açılardan fotoğrafları Şekil 2’ de verilmiștir.
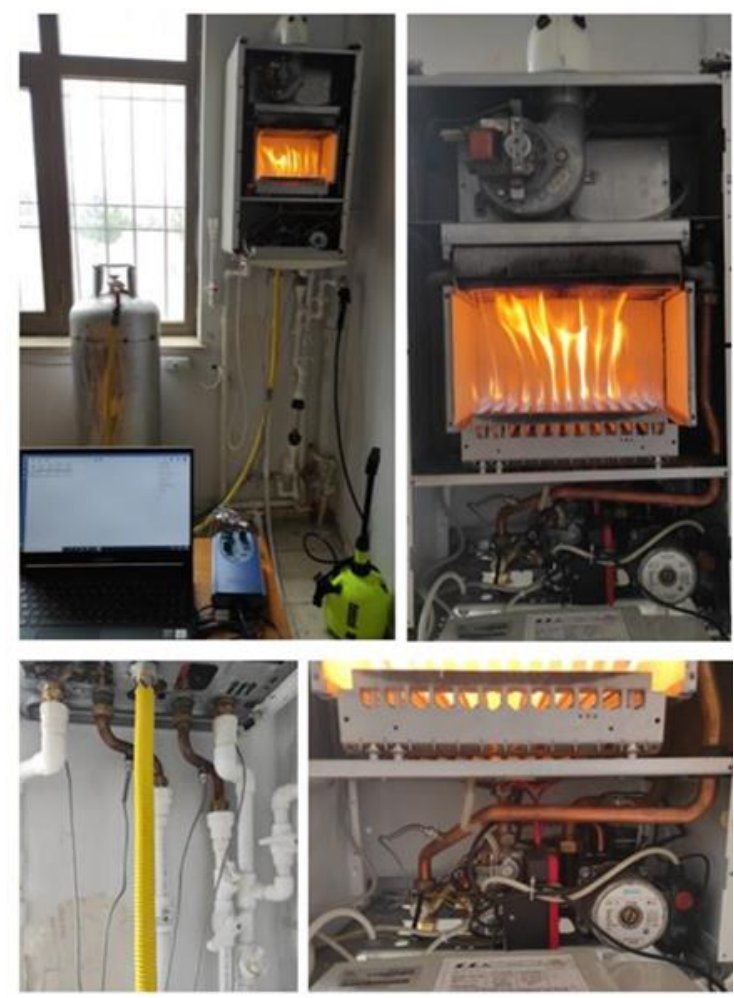

Şekil 2. Deney Setinin Görünümü

\subsection{Deneyde Kullanılan Nano Partikül ve Saf Suyun Özellikleri}

Nano parçacıklar kimyasal yapıları farklı olan malzemeler kullanılarak üretilmekte olup, metaller, seramikler, silikatlar, metal oksitler, organik ve karbon malzemeler örnek olarak verilebilir. Bu çalışmada grafit nano partikülleri kullanılarak nanoakışkan oluşturulmuştur. Nanoakışkanı oluşturmak için kullanılan grafit nano partikülüne ve saf suya ait termofiziksel özellikler Tablo 1'de görülmektedir.
Tablo 1. Grafit Nano Partikülün ve Saf Suyun Termofiziksel Özellikleri

\begin{tabular}{l|l|c}
\hline Özellikler & Grafit & Saf Su \\
\hline$\rho\left(\mathrm{kg} / \mathrm{m}^{3}\right)$ & 2300 & 992 \\
\hline$C p(\mathrm{~J} / \mathrm{kgK})$ & 711 & 4182 \\
\hline$k(\mathrm{~W} / \mathrm{mK})$ & 168 & 0,618 \\
\hline$\mu(\mathrm{mPa} . \mathrm{s})$ & - & 0,62 \\
\hline
\end{tabular}

\subsection{Deneyde Kullanılan Nanoakışkanın Hazırlanması}

Deney setinde kullanılan grafit nano partikülleri Nanografi firmasından temin edilmiștir. Nanoakıșkan İnönü Üniversitesi Mühendislik Fakültesi Gıda Mühendisliği Laboratuvarında hazırlanmıştır. Grafit nano partiküller istenen hacimsel konsantrasyonda karışım yapabilmek için $0,1 \mathrm{mg}$ hassasiyetli hassas terazi kullanılmıștır. Daha sonra kütlesel oran hacimsel orana dönüştürülmüştür. Hacimce $\% 0,25$ konsantrasyonunda nanoakışkan hazırlamak amacıyla 4 litre saf suya 23 gr grafit parçacıkları ilave edilmiştir. Grafit-su nanoakışkanı iki aşamalı yöntem kullanılarak hazırlanmıștır. Bu yöntemde temel akışkan ile nano parçacıkların kümeleşmesini ve çökelmeyi engellemek için ultrasonifikatör cihazı kullanılmıştır. Bu cihaz ile ultrasonik titreșimler meydana getirilmektedir. Tartım ișlemi yapılan grafit nano parçacı̆̆ı temel akıșkan saf su ile karıștırılmıș ve nanoakışkanın kararlılığının elde edilebilmesi için 5 saatlik süre esnasında 63 Hz'lik frekansa ve 400 watt güce sahip Hiel Sher Up 400 ST ultrasonifikatör cihazında bekletilmiştir. Grafit nano parçacıklarının birbirine yaklaşmasını ve çökelmeyi engellemek için $0,69 \mathrm{~g}$ benzen sülfonat eklenerek Ika T25 digital homojenizatör cihazında mekanik olarak 3 saat boyunca 3000 dev/dak bekletilmiștir. Nanoakıșkanın hazırlanmasında yapılan işlemlere ait resimler Şekil 3 ’te gösterilmektedir.

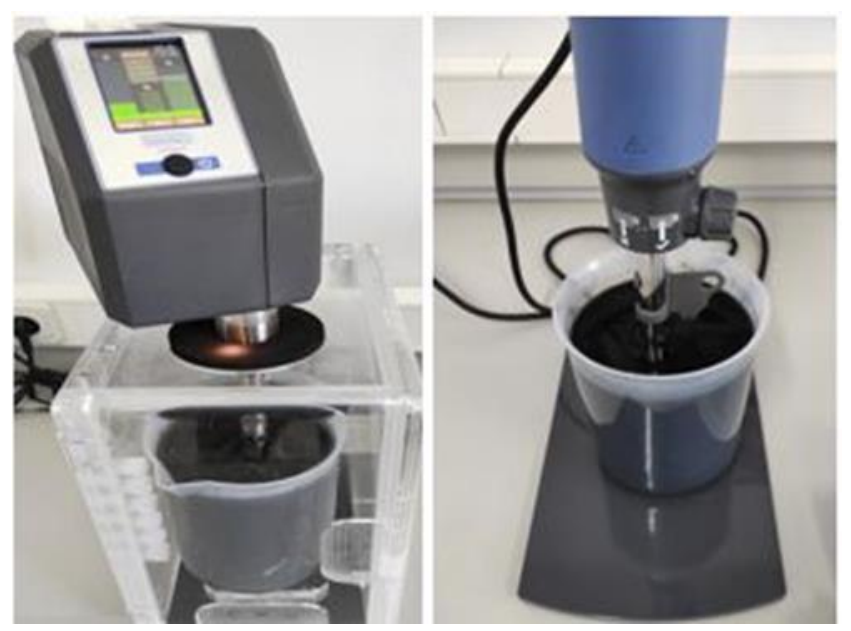

Sekil 3. Ultrasonifikatör ve Homojenizatör

\subsection{Teorik Analiz}

Nanoakışkan yoğunluğu Pak ve Choi modeli ile tahmin edilmekte olup denklem 1 kullanılarak hesaplanmaktadır (Pak ve Choi, 1998). Burada $\rho$ yoğunluk, $n$ nano partikülleri, f temel sıvıyı ve nf nano sıvıyı simgelemektedir. Nano partiküllerin hacimsel oranı $(\phi)$ ile gösterilmektedir. 


$$
\rho_{\mathrm{nf}}=\phi \cdot \rho_{\mathrm{n}}+(1-\phi) \cdot \rho_{\mathrm{f}}
$$

Nanakışkanın özgül 1sıs1, Xuan ve Roetzel modeli kullanılarak denklem 2 ile hesaplanmaktadır (Xuan ve Roetzel, 2000). Burada $C_{p}$ özgül ısıdır.

$$
\mathrm{C}_{\mathrm{p}, \mathrm{nf}}=\frac{\emptyset \cdot\left(\rho_{\mathrm{n}} \cdot \mathrm{C}_{\mathrm{p}, \mathrm{n}}\right)+(1-\emptyset) \cdot\left(\rho_{\mathrm{f}} \mathrm{C}_{\mathrm{p}, \mathrm{f}}\right)}{\rho_{\mathrm{nf}}}
$$

Hazırlanan nanoakışkanın ısıl iletkenliği Maxwell-Garnet modeli kullanılarak denklem 3 ile belirlenmektedir (Maxwell ve Garnett, 1904). Burada k termal iletkenliktir.

$$
\mathrm{k}_{\mathrm{nf}}=\mathrm{k}_{\mathrm{f}} \frac{\mathrm{k}_{\mathrm{n}}+2 \mathrm{k}_{\mathrm{f}}-2 \varnothing\left(\mathrm{k}_{\mathrm{f}}-\mathrm{k}_{\mathrm{n}}\right)}{\mathrm{k}_{\mathrm{n}}+2 \mathrm{k}_{\mathrm{f}}+\emptyset\left(\mathrm{k}_{\mathrm{f}}-\mathrm{k}_{\mathrm{n}}\right)}
$$

Nano partiküllerin hacimsel oranı denklem 4 ile hesaplanmaktadır. Burada $m_{n}$ ve $m_{f}$ nano partiküllerin ve temel sıvının kütlesidir.

$$
\phi=\frac{\mathrm{m}_{\mathrm{n}} / \rho_{\mathrm{n}}}{\mathrm{m}_{\mathrm{n}} / \rho_{\mathrm{n}}+{ }^{\mathrm{m}_{\mathrm{f}}} / \rho_{\mathrm{f}}}
$$

Transfer edilen 1S1 miktarı denklem 5 ile kullanılarak hesaplanmaktadır. Burada Q, 1s1 transferi miktarı, m, kütlesel debi $c_{p c}, c_{p h}$ sırasıyla soğuk ve sıcak akışkanın özgül ısısıdır.

$$
\mathrm{Q}=\dot{\mathrm{m}}_{\mathrm{h}} \cdot \mathrm{c}_{\mathrm{ph}} \cdot\left(\mathrm{T}_{\mathrm{hi}}-\mathrm{T}_{\mathrm{ho}}\right)=\dot{\mathrm{m}}_{\mathrm{c}} \cdot \mathrm{c}_{\mathrm{pc}} \cdot\left(\mathrm{T}_{\mathrm{ci}}-\mathrm{T}_{\mathrm{co}}\right)
$$

Plaka tip 1sı değiştiricide sıcak ve soğuk suyun 1sı kapasitesi denklem 6 ve denklem 7 ile hesaplanmaktadır.

$$
\begin{aligned}
& C_{\text {hot }}=\dot{\mathrm{m}}_{\mathrm{h}} \cdot \mathrm{c}_{\mathrm{ph}} \\
& C_{\text {cold }}=\dot{\mathrm{m}}_{\mathrm{c}} \cdot \mathrm{c}_{\mathrm{pc}}
\end{aligned}
$$

Isı değiştiricide gerçekleştirilebilecek maksimum 1s1 transferi miktarını bulmak için bu değerlerden küçük olan değer $C_{\min }$ olarak kullanılır. Denklem 8 ile hesaplanan $\mathrm{Q}_{\max }$ plakalı 1s1 değiştiricide gerçekleştirilebilecek maksimum 1S1 transferi miktarıdır.

$$
\mathrm{Q}_{\max }=\mathrm{C}_{\min } \cdot\left(\mathrm{T}_{\mathrm{hi}}-\mathrm{T}_{\mathrm{ci}}\right)
$$

Isı değiştiricinin etkinliği denklem 9 ile hesaplanır. Burada $\varepsilon$ etkinlik katsayısıdır (Selbaş ve ark., 2009).

$$
\varepsilon=\frac{\mathrm{Q}}{\mathrm{Q}_{\max }}
$$

İyileştirme oranı denklem 10 yardımıyla hesaplanmaktadır.

$$
\text { İyileştirme Oranı }=\frac{\left(\varepsilon_{\text {Grafit- }} \varepsilon_{S u}\right)}{\varepsilon_{S u}}
$$

\section{5. Ölçüm Hassasiyetleri}

Plakalı 1sı değiştiricisinde nanokışkan ve saf su ile yapılan deneylerde soğuk su giriş-çıkış sıcaklıkları ve debisi, sıcak su giriş-çıkış sıcaklıkları ve debisi ölçümleri tekrarlanarak yapılmıştır. Test edilen ve ölçüm yapan cihazlara ait katalog değerlerinden elde edilen hassasiyetler Tablo 2'de verilmektedir.
Tablo 2. Ölçüm Cihazlarının Hassasiyetleri

\begin{tabular}{l|l|l}
\hline Cihazlar & Teknik Özellikler & Hassasiyet \\
\hline $\begin{array}{l}\text { Slcaklık } \\
\text { ölçer }\end{array}$ & Ölçüm aralığ $-200 / 1200^{\circ} \mathrm{C}$ & $\pm 0,1^{\circ} \mathrm{C}$ \\
\hline $\begin{array}{l}\text { Hacimsel } \\
\text { debi ölçer }\end{array}$ & $2-18 \mathrm{1} / \mathrm{dk}$ & $\% 4$ \\
\hline $\begin{array}{l}\text { Hassas } \\
\text { terazi }\end{array}$ & Kapasite: $6000 \mathrm{gr}$ & $\pm 0,01 \mathrm{mg}$ \\
\hline $\begin{array}{l}\text { Veri kayıt } \\
\text { cihazı }\end{array}$ & $8 \quad$ kanallı, -270/1820 $\mathrm{C}$ & $\pm 0,001^{\circ} \mathrm{C}$ \\
\hline
\end{tabular}

\section{Araştırma Sonuçları ve Tartışma}

Şekil 4 ’te soğuk akışkanın debisi 4 1/dk iken, sıcak ve soğuk akışkanın etkinlik katsayısı sıcak akışkanın giriş sıcaklığının yükselmesiyle doğru orantılı artmıştır. Plakalı ısı değiştiricisine $40^{\circ} \mathrm{C}$ sıcaklıkta giren grafit-su nanoakışkanı ile yapılan deneylerde etkinlik 0,787 iken, saf su ile yapılan deneylerde etkinlik 0,739 olarak görülmektedir.

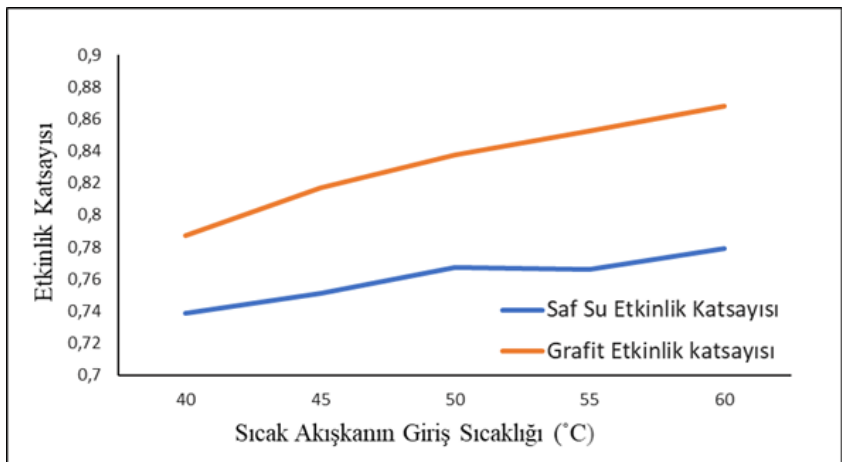

Şekil 4. Sıcak Akışkan Giriş Sıcaklı̆̆ı -Etkinlik Katsayısı Değişimi (Debi $4 \mathrm{l} / \mathrm{dk}$ )

Şekil 5'te görüldüğü gibi soğuk akışkan debisinin 5 1/dk olduğu deneylerde, grafit-su nanoakışkanın etkinlik katsayısı sıcak akışkanın giriş sıcaklığının artmasıyla doğru orantılı olarak artmış, saf suyun etkinlik katsayısı ise $40-50^{\circ} \mathrm{C}$ aralığında sıcaklık artışına bağlı olarak artış göstermiş, bu artış $50^{\circ} \mathrm{C}$ ile $55^{\circ} \mathrm{C}$ sıcaklıklar arasında ise minimum düzeyde kalmıştır. Daha sonra sıcaklığa bağlı olarak artmaya devam etmiştir. $40^{\circ} \mathrm{C}$ giriş sıcaklığında grafit-su nanoakışkanı ile yapılan deneylerde etkinlik 0,735 iken, saf su ile yapılan deneylerde etkinlik 0,699 olarak görülmüştür.

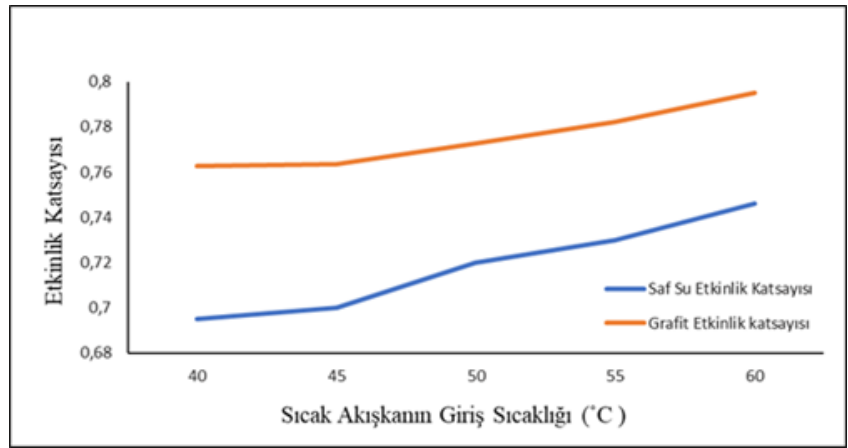

Şekil 5. Sıcak Akışkan Giriş Sıcaklı̆̆ı -Etkinlik Katsayısı Değişimi (Debi $5 \mathrm{l} / \mathrm{dk}$ ) 
Şekil 6'da soğuk akışkan debisinin 6 1/dk olduğu deneylerde, sıcak ve soğuk akışkanın etkinlik katsayısı sıcak akışkanın giriş sıcaklığına bağlı olarak artışı görülmektedir. $40^{\circ} \mathrm{C}$ giriş sıcaklığında grafit-su nanoakışkanı ile yapılan deneylerde etkinlik 0,690 iken, saf su ile yapılan deneylerde etkinlik 0,630 olarak görülmüştür.

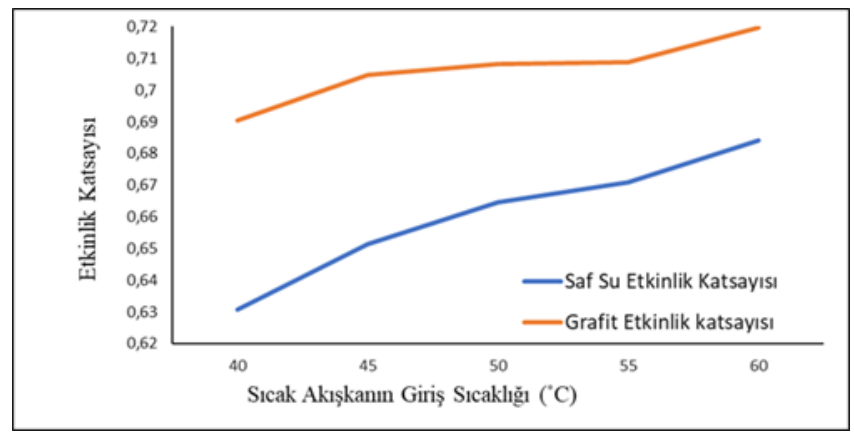

Şekil 6. Sıcak Akışkan Giriş Sicaklı̆̆ -Etkinlik Katsayısı Değişimi (Debi $6 \mathrm{l} / \mathrm{dk}$ )

Şekil 7'de debi 7 1/dk olarak alınmış olup, her iki akışkanın etkinlik katsayısı sıcak akışkanın giriş sıcaklığının artmasıyla doğru orantılı olarak yükseldiği gösterilmektedir. Giriş sıcaklığının $40^{\circ} \mathrm{C}$ olduğu grafit- su nanoakışkanı ile yapılan deneylerde etkinlik 0,632 iken, saf su ile yapılan deneylerde etkinlik 0,607 olarak tespit edilmiştir.

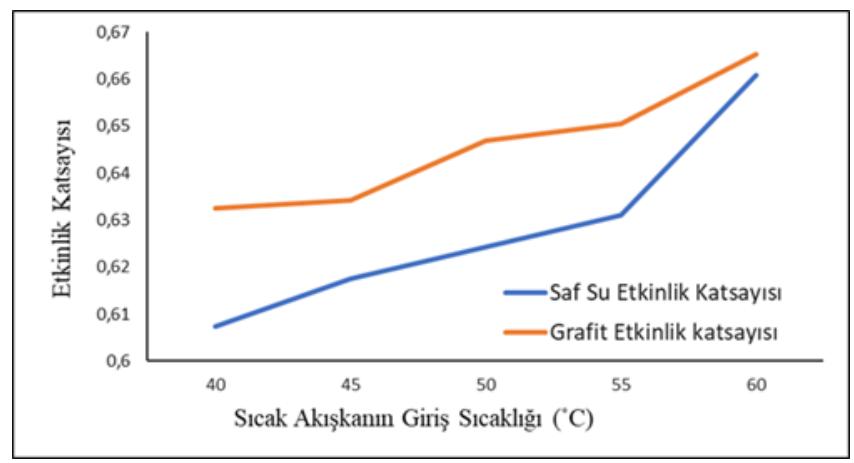

Şekil 7. Sicak Akışkan Giriş Sicakllğg -Etkinlik Katsayısı Değişimi (Debi $7 \mathrm{l} / \mathrm{dk}$ )

Toplam 1sı transferinin değişimi, farklı akışkan debileri ve farklı sıcaklıklara bağlı olarak Şekil 8'de verilmiştir. Debinin artışına bağlı olarak toplam ısı transferi miktarı da artmıştır. 4, 5, 6 ve 7 l/dk debilerde; $40^{\circ} \mathrm{C}$ sıcak akışkan giriş sıcaklıklarında toplam is1 transferi sirasiyla $3758 \mathrm{~W}, 4567 \mathrm{~W}, 5263 \mathrm{~W}$ ve $5401 \mathrm{~W}$ olurken, $60^{\circ} \mathrm{C}$ giriş sıcaklığında $7917 \mathrm{~W}, 10199 \mathrm{~W}, 10298 \mathrm{~W}$ ve $12321 \mathrm{~W}$ olarak elde edilmiştir.

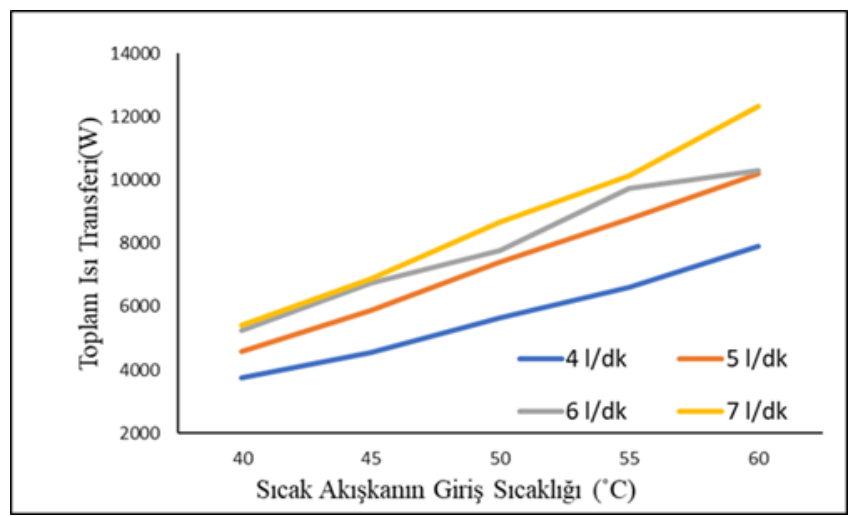

Şekil 8. Farklı Akışkan Debileri İçin Sıcak Akışkan Giriş Sıcaklı̆̆ına Bağlı Toplam Isı Transferi Miktarı
Şekil 9'da zit yönlü paralel akışlı plakalı 1Sı değiştiricide, farklı debilerde yapılan deneylerde saf su yerine grafit-su nanoakışkanı kullanıldığı durumda ortalama iyileştirme oranı grafiğgi görülmektedir. 4, 5, 6, 7 1/dk debi değerlerinde ortalama iyileştirme oranı sırasıyla $\% 9,42, \% 7,59, \% 7,21$ ve $\% 2,85$ olarak hesaplanmıştır. Debinin artışına bağlı olarak iyileştirme oranının azaldığı görülmektedir.

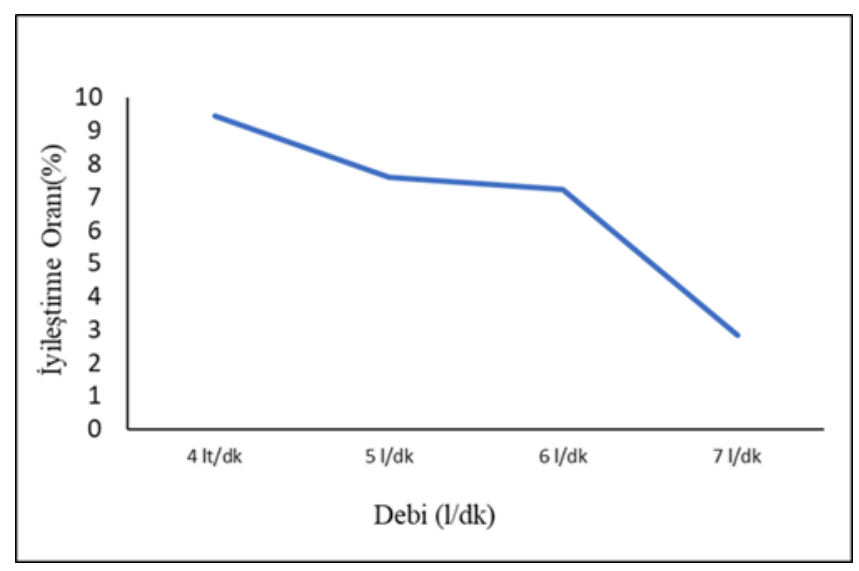

Şekil 9. Debiye Göre İyileştirme Oranı Değişimi

\section{Sonuç}

Yapılan bu çalışma ile su içinde grafit nano partiküllerin varlığının, 1sı transferi, etkinlik katsayısı ve iyileştirme oranına etkileri incelenmiştir. $\mathrm{Bu}$ amaçla su içerisine hacimce $\% 0,25$ oranında nano partikül eklenmiş ve toplam 1 sı transferi, etkinlik katsayısı ve iyileștirme oranı incelenmiştir. Deneylerden elde edilen etkinlik katsayıları ve iyileştirme oranı değerleri Tablo 3'de verilmiştir.

Tablo 3. Etkinlik Katsayıları ve İyileştirme Oranları

\begin{tabular}{|c|c|c|c|c|c|c|c|}
\hline \multirow[t]{2}{*}{ Akışkan Tipi } & \multirow{2}{*}{$\begin{array}{r}\text { Debi } \\
\text { l/dk }\end{array}$} & \multicolumn{5}{|c|}{$\begin{array}{c}\text { Sicaklıklara Göre Etkinlik } \\
\text { Katsayısı }\end{array}$} & \multirow{2}{*}{$\begin{array}{l}\text { İyileştirme } \\
\text { Oranı (\%) }\end{array}$} \\
\hline & & $40^{\circ} \mathrm{C}$ & $45^{\circ} \mathrm{C}$ & $50^{\circ} \mathrm{C}$ & $55^{\circ} \mathrm{C}$ & $60^{\circ} \mathrm{C}$ & \\
\hline Saf su & \multirow{2}{*}{4} & 0,739 & 0,75 & 0,767 & 0,765 & 0,779 & \multirow{2}{*}{9,42} \\
\hline Nanoakışkan & & 0,787 & 0,817 & 0,837 & 0,852 & 0,867 & \\
\hline Saf su & \multirow{2}{*}{5} & 0,695 & 0,699 & 0,72 & 0,73 & 0,746 & \multirow{2}{*}{7,59} \\
\hline Nanoakışkan & & 0,762 & 0,763 & 0,772 & 0,782 & 0,794 & \\
\hline Saf su & \multirow{2}{*}{6} & 0,63 & 0,651 & 0,664 & 0,67 & 0,684 & \multirow{2}{*}{7,21} \\
\hline Nanoakışkan & & 0,69 & 0,704 & 0,708 & 0,708 & 0,719 & \\
\hline$\underline{S a f s u}$ & \multirow{2}{*}{7} & 0,607 & 0,617 & 0,624 & 0,631 & 0,66 & \multirow{2}{*}{2,85} \\
\hline Nanoakışkan & & 0,632 & 0,634 & 0,646 & 0,65 & 0,665 & \\
\hline
\end{tabular}

Elde edilen sonuçlar incelendiğinde 4, 5, 6, 7 1/dk soğuk akışkan debileri için nanoakışkanın etkinlik katsayısı saf suyla kıyaslandığında önemli ölçüde artmıştır. Fakat debinin artmasına bağlı olarak etkinlik katsayısının artış miktarı giderek azalmıştır. Toplam 1s1 transferi 4, 5, 6, 7 1/dk debileri için debinin ve sıcaklığın artışıyla doğru orantılı olarak artmıştır. Ortalama iyileştirme oranı ise $4 \mathrm{l} / \mathrm{dk}$ debide en yüksek değerine ulaşmış olup, debinin artmasına bağlı olarak bu değer düşme eğilimine girmiştir. $\mathrm{Bu}$ sonuçlara göre nanoakışkan ile saf su karşılaştırıldığında, plakalı 1S1 değiştiricisinde nanoakışkan kullanımı ile 1sıl verimlilikte önemli iyileştirmeler sağlanmıştır. Isıl verimlilikte nanoakışkanların termofiziksel özellikleri, nanoakışkanın konsantrasyon seviyesi, isı değiştiricinin geometrisi etkili olup, sıcaklıklar ve akışkan debisi gibi çalışma koşulları da önemli etkenlerdir. Nanoakışkan kullanımının 
olumsuz yönleri ise maliyetin yüksek olması, uygun oranda hazırlanmaması durumunda çökelme, tortulaşma gibi durumlardır. Özellikle nanoakışkanlarda çökelmenin olmaması için karışım hazırlama işlemine oldukça önem verilmeli ve hassas davranılmalıdır. Isı değiştiricilerinde deneysel çalışma yapacak araştırmacıların belirtilen durumları göz önünde bulundurmaları gerekmektedir. Isı değiştiricilerinde nanoakışkanların ısı transferi ve basınç düşüşü üzerindeki etkisini araştırmak için farklı konsantrasyonlarda grafit-su nanoakışkanı kullanılarak yeni çalışmalar yapılabilir. Ayrıca plaka tip ısı değiştiricilerinde farklı tip nanoakışkan kullanarak nanoakışkanlar 1 sıl performans açısından karşıılaştırılabilir.

\section{Teşekkür}

Bu çalışmayı (FYL-2020-2253) proje kodu ile destekleyen İnönü Üniversitesi Bilimsel Araştırma Projeleri Birimine teşekkür ederiz. Ayrıca nanoakışkan İnönü üniversitesi Gıda Mühendisliği Laboratuvarında hazırlanmış olup, bu konuda yardımcı olan Prof. Dr. Ali Adnan Hayaloğlu'na teşekkür ederiz.

\section{Kaynakça}

Bhattad, A., Sarkar, J., Ghosh, P. (2018). Discrete phase numerical model and experimental study of hybrid nanofluid heat transfer and pressure drop in plate heat exchanger. International Communications in Heat and Mass Transfer, 91, 262-273.

Chun B.H., Kang H.U., Kim S.H. (2008). Effect of alumina nanoparticles in the fluid on heat transfer in double-pipe heat exchanger system. Korean Journal of Chemical Engineering, 25(5), 966-971.

Huang, D., Wu, Z. (2016). Sunden B, Effects of hybrid nanofluid mixture in plate heat exchangers. Experimental Thermal and Fluid Science, 72, 190-196.

Maxwell, J.C., Garnett, J.C. (1904). Colours in metal glasses and in metallic films. Philosophical Transactions of the Royal Society a Mathematical, Physical and Engeneering Sciences, 203, 385-420.

Pak, B.C., Choi, Y.I. (1998). Hydrodynamic and heat transfer study of dispersed fluids with submicron metallic oxide particle. Experimental Heat Transfer and International Journal, 11 (2), 151-170.

Sarafraz, M.M., Hormozi, F. (2016). Heat transfer pressure drop and fouling studies of multi-walled carbon nanotube nanofluids inside a plate heat exchanger. Experimental Thermal and Fluid Science, 72, 1-11.

Selbaş, R., Sencan, A.M., Kılıç, B. (2009). Alternative approach in thermal analysis of plate heat exchanger. Heat and Mass Transfer, 45, 323-329.

Variyenli, H.İ., Sar1, Y. (2016). Magnezyum oksit ile saf suyun plaka tip isı değiştiricideki isıl performanslarının deneysel incelenmesi. Gazi Mühendislik Bilimleri Dergisi, 2(3), 147170.

Xuan, Y., Roetzel, W. (2000). Conceptions for heat transfer correlation of nanofluids. International Journal of Heat and Mass Transfer, 43(19), 3701-3707.

Zamzamian, A., Oskouie, S.N., Doosthoseini, A., Joneidi, A., Pazouki, M. (2011). Experimental investigation of forced convective heat transfer coefficient in nanofluids of $\mathrm{Al}_{2} \mathrm{O}_{3} / \mathrm{EG}$ and $\mathrm{Cuo} / \mathrm{EG}$ in a double pipe and plate heat exchangers under turbulent flow. Experimental Thermal and Fluid Science, 35, 495-502. 